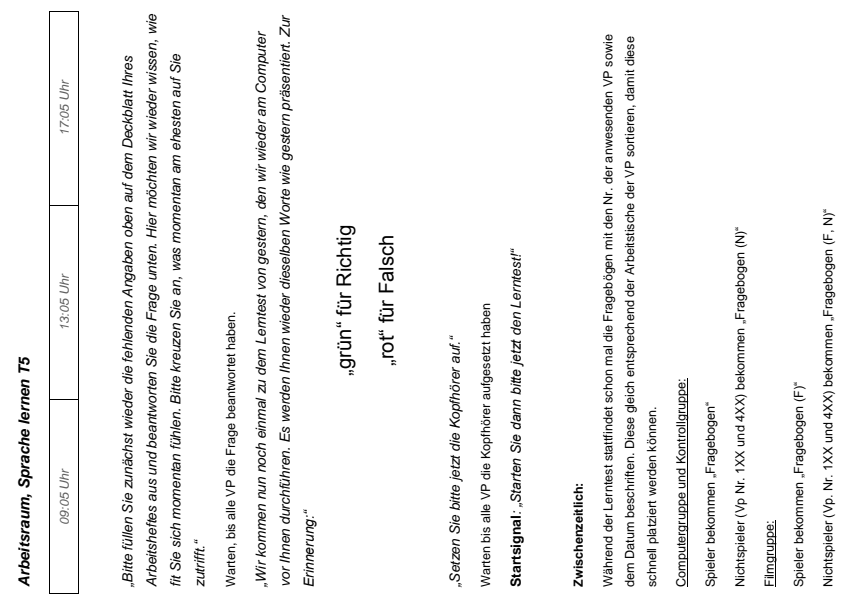

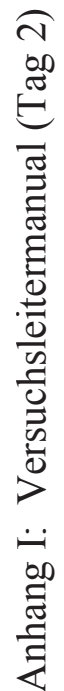

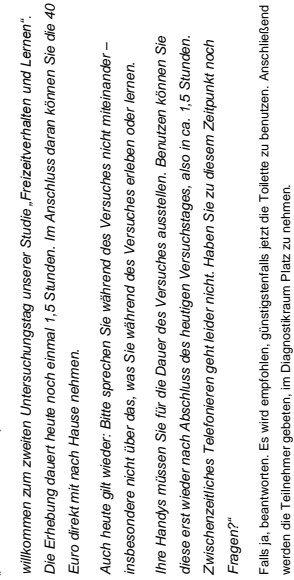



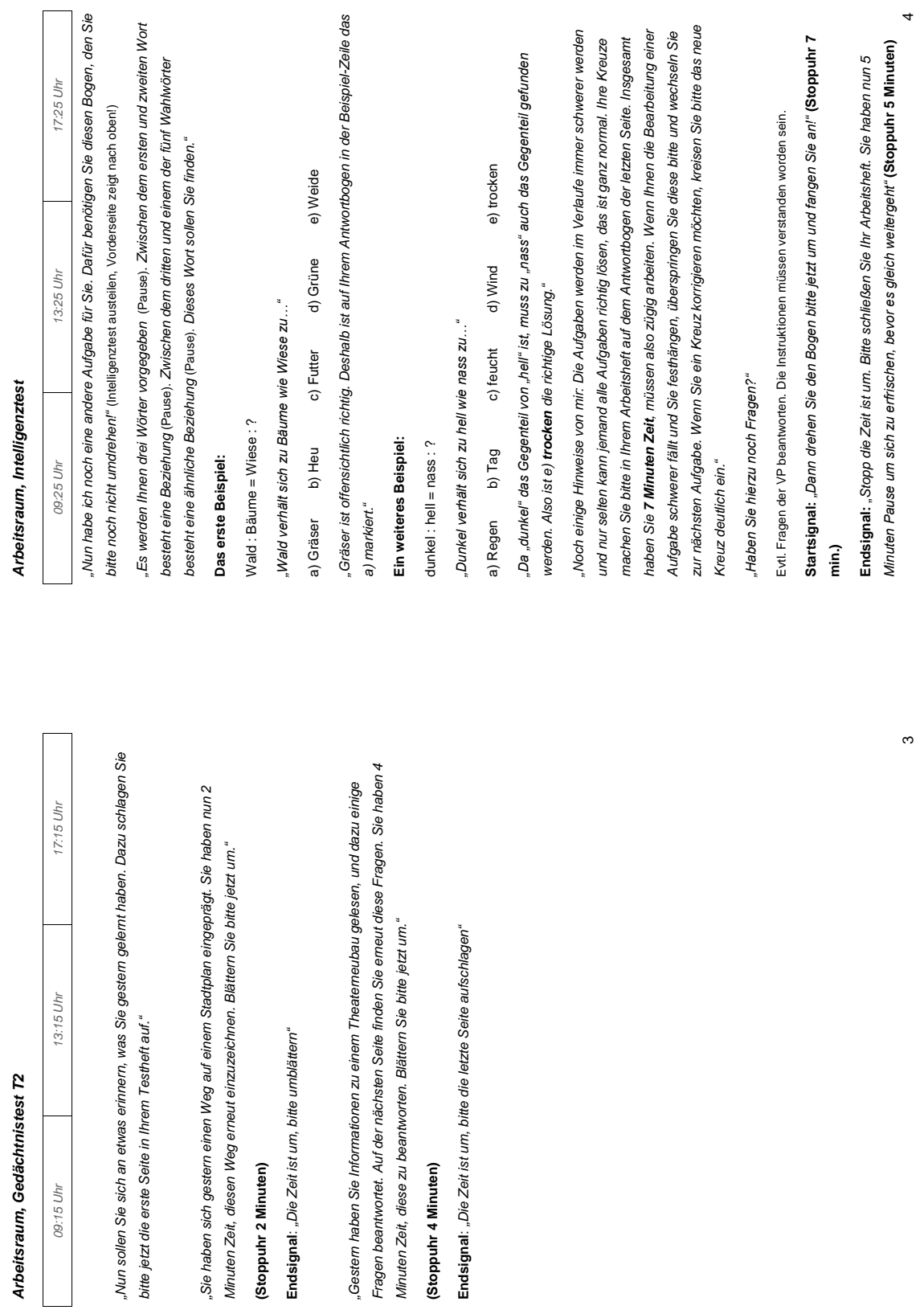


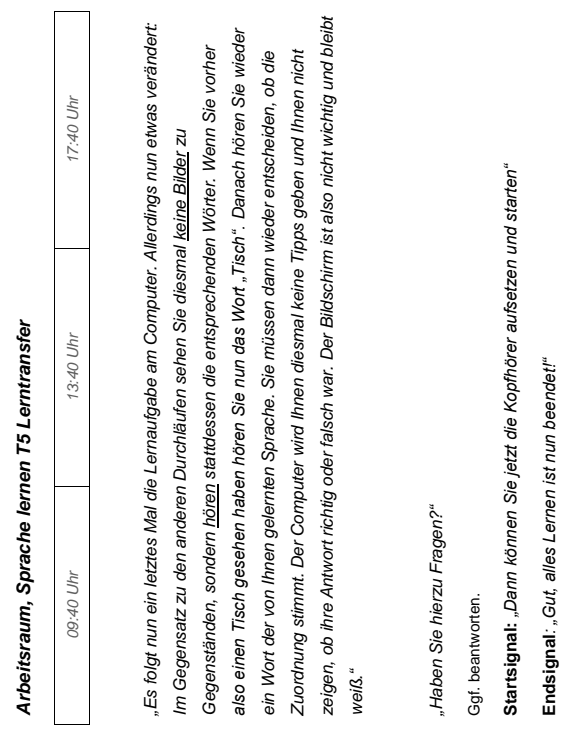

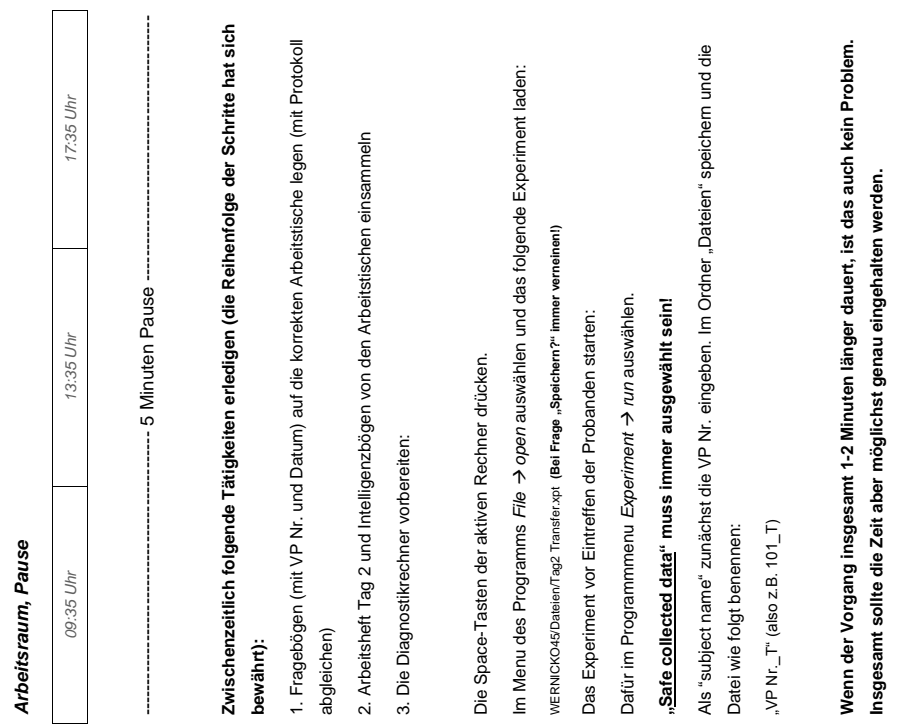



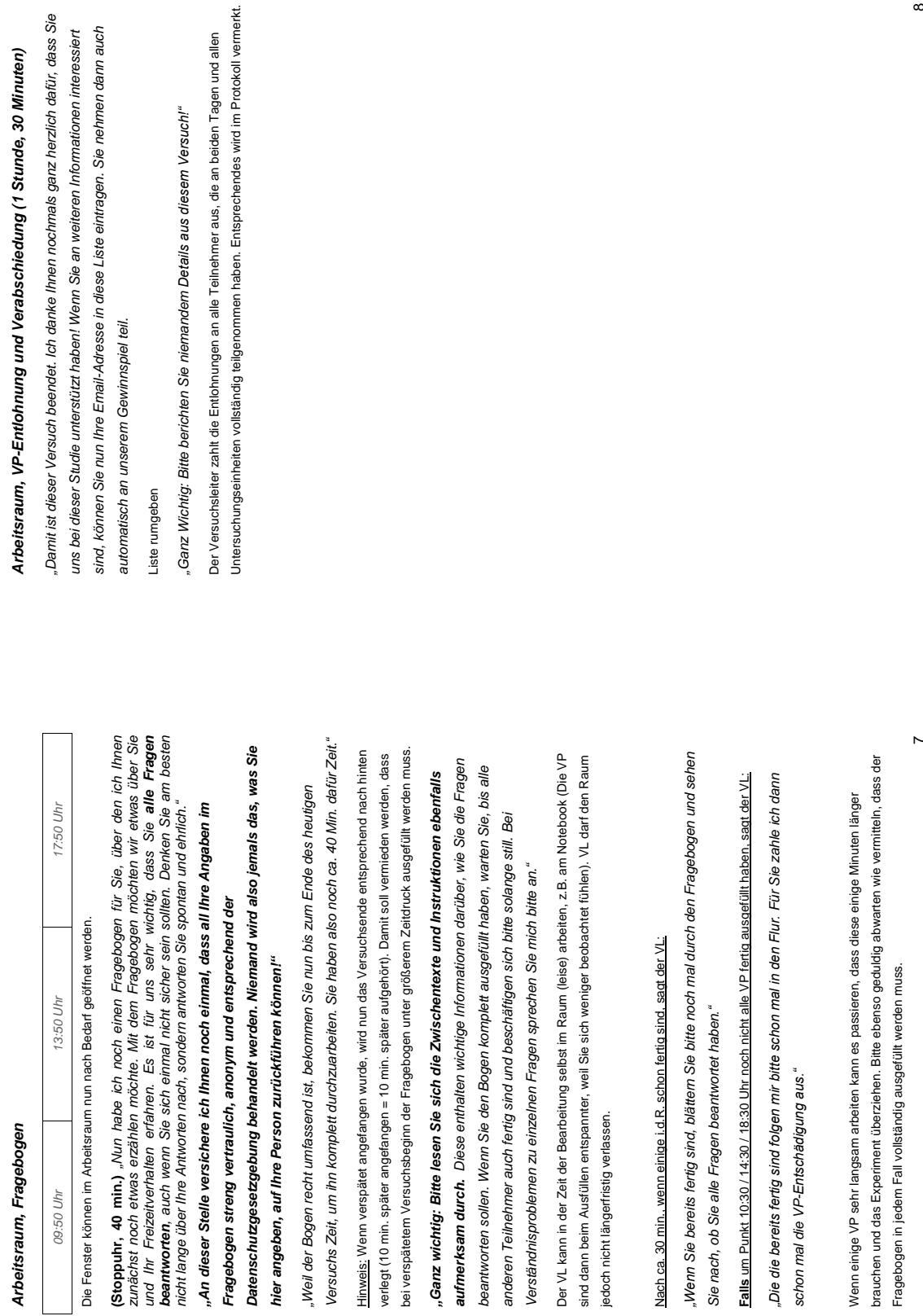


\section{Anhang J: Post-Hoc-Poweranalysen}

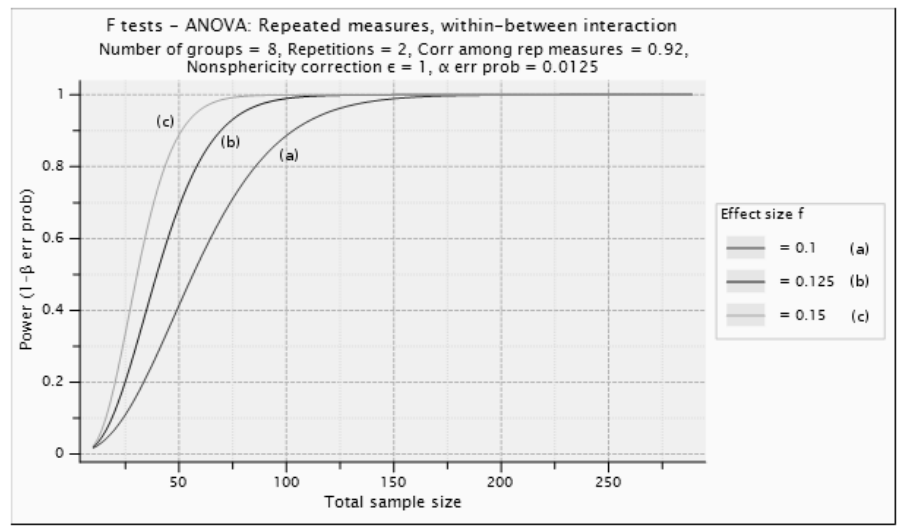

Ergebnisse der Post-Hoc-Poweranalyse zur durchgeführten messwiederholten Varianzanalyse Konzentrationsleistung (KLT-R). Realisierte Teststärke unter der Annahme kleiner bis mittelkleiner Populationseffekte (rechtsseitiges Ende der Kurven entspricht der realisierten Stichprobe von $\mathrm{N}=289$ )

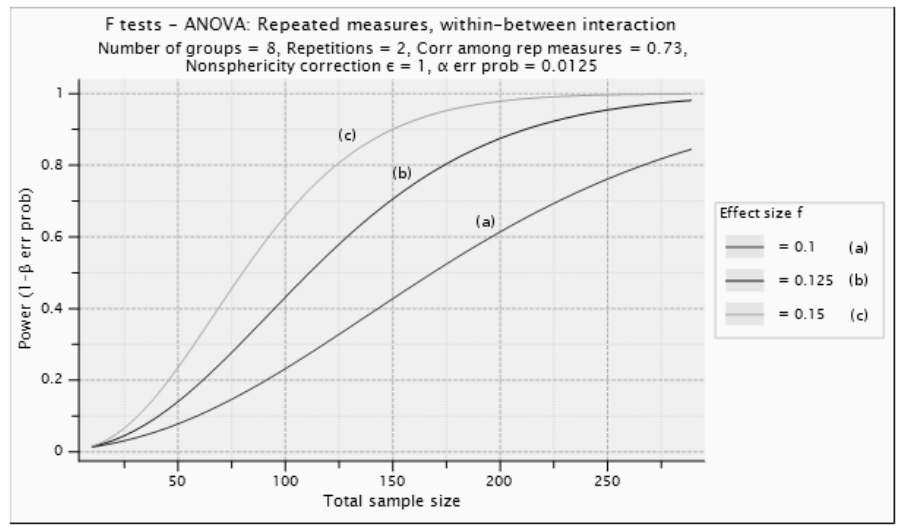

Ergebnisse der Post-Hoc-Poweranalyse zur durchgeführten messwiederholten Varianzanalyse räumliche Gedächtnisleistung (VVM). Realisierte Teststärke unter der Annahme kleiner bis mittelkleiner Populationseffekte (rechtsseitiges Ende der Kurven entspricht der realisierten Stichprobe von N =289) 